Patryk Chudzik

Uniwersytet Wrocławski

Mateusz Żmudziński

ORCID: 0000-0002-5771-6099

Uniwersytet Wrocławski

\title{
Rola Nilu w kształtowaniu kultury starożytnego Egiptu
}

Abstrakt: W artykule autorzy zwracają uwagę na wieloaspektowe związki pomiędzy Nilem a kulturą i cywilizacją starożytnego Egiptu. Wskazywane są zarówno sprawy gospodarcze, jak i kulturotwórcze. Nil bowiem żywił, poił, nawadniał pola, służył jako trasa komunikacyjna, ale co więcej — przeszedł do wierzeń i świata kultury Egipcjan. Regulacja rytmu życia ludu, jego organizacja społeczna, zachowania kultowe, rytualne polowania, sposoby spędzania wolnego czasu czy rozliczne dzieła sztuki wiązały się z Nilem. Trudno wręcz w Egipcie czasów faraonów znaleźć coś, co się z nim nie wiązało. Był to kluczowy czynnik, który przez tysiące lat wpływał na życie ludzi w Egipcie.

Słowa-klucze: Nil, gospodarka, kultura, wierzenia, sztuka, organizacja społeczna

Badając dawne kultury, musimy zawsze zdawać sobie sprawę z odziaływań człowieka na środowisko naturalne. Najlepszym tego dowodem archeologicznym jest wytwarzany przez człowieka asortyment przedmiotów. Jednocześnie, na co słusznie zwrócono uwagę w literaturze naukowej, zachodzi interakcja pomiędzy człowiekiem a jego otoczeniem ${ }^{1}$. Ludzie są bowiem zależni zarówno od środowiska naturalnego, jak i zespołu przedmiotów codziennego użytku, w tym narzędzi, które wprost uzależniają społeczeństwa i kierują je ku określonym formom zachowania ${ }^{2}$. Środowisko w znacznej mierze determinowało działania ludzi i tworzonych przez nich wspólnot, a wytwory rąk ludzkich ułatwiały coraz to dalszy

${ }^{1}$ I. Hodder, Entangeld. An Archaeology of the Relationships between Humans and Things, Malden 2012, s. 10-14.

2 Ibidem, s. 17 n. 
rozwój społeczeństw. Znakomitym przykładem takiej sytuacji jest oddziaływanie pomiędzy mieszkańcami starożytnego Egiptu a Nilem.

Egipt położony jest w północno-wschodnim narożniku Afryki. Z południa na północ przez obszar ten przepływa Nil — najdłuższa rzeka na Ziemi, która dzieli Egipt na Pustynię Wschodnią (Arabską) i Pustynię Zachodnią (Libijską). Źródła Nilu znajdują się daleko w głębi Afryki. Rzeka w swoim górnym biegu znana jest jako Nil Biały i wypływa z Jeziora Wiktorii, kierując się na północ. W okolicach Chartumu łączy się z Nilem Błękitnym, tworząc rzekę Nil. Cywilizacja starożytnego Egiptu rozwinęła się nad brzegami Nilu w jego końcowym biegu pomiędzy I Kataraktą w okolicach dzisiejszego Asuanu a Morzem Śródziemnym, do którego rzeka uchodzi. Na tym odcinku rzeka wyżłobiła w pustynnym płaskowyżu szeroki wąwóz, nanosząc na okoliczne tereny grubą warstwę urodzajnego mułu z głębi kontynentu afrykańskiego. W północnej części Egiptu Nil tworzy natomiast rozległą płaską deltę przeciętą dwoma jego odnogami, znanymi jako: Damietta na wschodzie i Rosetta na zachodzie, a także ich licznymi odpływami.

Podział geograficzny miał również swoje odzwierciedlenie polityczne, gdyż kraj faraonów zawsze składał się z dwóch części: Egiptu Górnego (dolina Nilu) i Dolnego (delta rzeki). Starożytni Egipcjanie określali swoje państwo jako Taui, czyli Oba Kraje, co potwierdza rozdźwięk terytorialny. Ponadto każda z części podzielona była na wiele mniejszych obszarów, które z języka greckiego obecnie nazywa się nomami. W Egipcie Górnym były to dwadzieścia dwa nomy, zaś w Dolnym, w zależności od okresu historycznego, od szesnastu do dwudziestu.

Ten dwoisty charakter kraju faraonów można dostrzec w wielu aspektach życia społeczności zaliczanej do kultury egipskiej, jak na przykład tytulatura królewska. Jednym z imion władcy, które wpisywano w kartusz ${ }^{3}$, było imię tronowe: nesut bity („Król Górnego i Dolnego Egiptu”, a dosłownie „Ten, który związany jest z trzciną

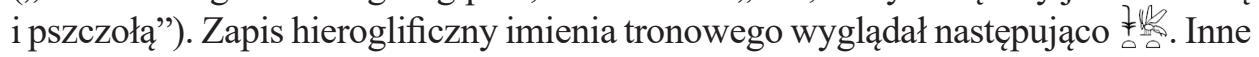
imię: nebti („Dwie Panie” lub „Dwie Boginie”) wskazywało natomiast na opiekę, jaką nad faraonem roztaczały boginie Nechebet i Uadżit — patronki odpowiednio Górnego i Dolnego Egiptu, przedstawiane jako sęp i kobra.

Starożytni Egipcjanie stosowali jeszcze jeden istotny podział terytorium swojego kraju, na co bezpośredni wpływ miał właśnie Nil. Otóż tereny uprawne, w obrębie których lokalizowane były wsie, osady i miasta, nazywano Kemet, czyli „Czarna ziemia”, co odnosiło się do koloru żyznego mułu nanoszonego przez rzekę i osadzającego się na polach. Z kolei te obszary, które znajdowały się poza granicami terenów rolnych i mieszkalnych, czyli niemalże zupełnie tereny pustynne lub górzyste, określano Deszeret, co znaczyło „Czerwona ziemia”.

${ }^{3}$ Kartusz był wydłużoną owalną ramką z poprzeczką u podstawy, w którą wpisywano imię władcy. W rzeczywistości kartusz przedstawiał pętlę ze sznura i był wydłużoną formą hieroglifu szen (eg. 'otaczać, okrążać'), co miało wskazywać na to, że władca panuje nad wszystkim, nad czym góruje słońce. 
Na długo jednak przed ukształtowaniem się kultury egipskiej i stworzeniem cywilizacji faraonów dolina Nilu była celem wędrówek grup ludzkich jedynie sezonowo. Chodzi tu o zbieracko-łowieckie społeczności okresu paleolitu, które wówczas zamieszkiwały głównie tereny Pustyni Zachodniej ${ }^{4}$. Przed tysiącami lat obszar Sahary pokrywała bowiem roślinność trawiasta charakterystyczna dla sawanny. Ludzie gromadzili się więc wówczas w obrębie niewielkich oaz, gdzie zakładali sezonowe obozowiska $^{5}$. W okresach suszy społeczności zbieracko-łowieckie migrowały w kierunku Nilu oraz jego licznych odnóg, które ukształtowały górskie doliny (wadi) po wschodniej i zachodniej stronie rzeki. Celem tych wędrówek był stały dostęp do wody, ale też surowców bogato występujących w poszczególnych partiach górskiego gebla. Na tych terenach pozyskiwano między innymi różne rodzaje krzemienia, z których wykonywano narzędzia i broń. Liczne stanowiska $z$ tego okresu, znane jako pracownie obróbki krzemienia, zostały odkryte w rozmaitych częściach Egiptu ${ }^{6}$.

Wyraźne przemiany związane ze zmianą klimatu nastąpiły na przełomie VII i VI tysiąclecia p.n.e. Postępujące pustynnienie rozległych terenów oraz wysychanie zbiorników wodnych tworzących rozsiane po Pustyni Zachodniej oazy spowodowało przeniesienie się grup ludzkich w obręb doliny Nilu, a w efekcie również rozwój społeczności, których podstawą funkcjonowania stała się gospodarka rolna ${ }^{7}$.

Przejście od gospodarki zbieracko-łowieckiej do stałej uprawy pól wpłynęło na budowę stałych osiedli położonych w sąsiedztwie Nilu ${ }^{8}$. Od tego momentu społeczności zaliczane przez archeologów do różnych kultur neolitycznych stały się zupełnie zależne od wielkiej rzeki, z czasem usiłując wykorzystać wynikające z niej możliwości dalszego rozwoju. Znajdowało to odzwierciedlenie w całym wachlarzu zjawisk związanych z kulturą, religią, gospodarką, a w efekcie ogólnym rozwojem cywilizacyjnym.

Największy wpływ na rozkwit kultury egipskiej miał charakter wylewów Nilu. Rzeka w sposób cykliczny, a jednocześnie bardzo obfity dostarczała nie tylko

${ }^{4}$ Zob. B. Midant-Reynes, The Prehistory of Egypt: From the First Egyptians to the First Pharaohs, przeł. I. Shaw, Oxford 2000, s. 33 n. oraz wymieniona tam literatura.

5 Ibidem, s. 21-22.

${ }^{6}$ G. Schweinfurth, Ein neuentdecker Tempel in Theben, „Zeitschrift für Ägyptische Sprache und Altertumskunde" 41, 1904, s. 22-25; idem, Über altpaläolitische Manufakte aus dem Sandsteingebiet von Oberägypten, „Zeitschrift für Ethnoogie” 5, 1909, s. 739-740; B. Drobniewicz, B. Ginter, J.K. Kozłowski, Topographie préhistorique du cirque de Deir el-Bahari, [w:] Deir el-Bahari (Habitat préhistorique), cz. 1, red. J.K. Kozłowski, „Prace Archeologiczne” 24, Kraków 1976, s. 17; B. Ginter, J.K. Kozłowski, B. Drobniewicz, Silexindustrien von El Târif, „Archäologische Veröffentlichungen" 26, Mainz 1986, s. 15-42; P. Chudzik, The tombs of Asasif: Archaeological exploration in the 2013/2014 season, „Polish Archaeology in the Mediterranean” 24, 2015, s. 133.

${ }^{7}$ S. Hendrick, P. Vermeersch, Prehistory. From the Palaeolithic to the Badarian Culture (c. 7,000,000-4000 BC), [w:] The Oxford History of Ancient Egypt, red. I. Shaw, Oxford 2000, s. $31-39$.

${ }^{8}$ K.W. Butzer, Early Hydraulic Civilization in Egypt. A Study in Cultural Ecology, Chicago-London 1976, s. 12-18. 
wodę, lecz także duże ilości żyznego mułu, który po odpływie przykrywał znaczne połacie pól, co sprzyjało urodzajnym zbiorom.

Jak słusznie zauważył Bjørnar Olsen, procesy dziejowe są wypadkową warunków i doświadczeń zbiorowych społeczeństw, które przez całe lata korzystają z pracy, wynalazków czy wiedzy minionych pokoleń ${ }^{9}$. Nil, w odróżnieniu od innych wielkich rzek świata, przez tysiące lat był stosunkowo przewidywalny. Cykliczny charakter wylewów miał w związku z tym wyraźny wpływ na rytm życia mieszkańców Egiptu. W okresie wylewu (achet), czyli w październiku i listopadzie, prąd rzeki znacząco zwalniał, akumulując na polach duże pokłady żyznego mułu, w którym dokonywano zasiewów. Następnie rozpoczynała się pora wzrostu (peret), która trwała aż do marca-kwietnia, zakończona zbiorami plonów, które dojrzewały w delikatnym zimowym słońcu. Latem ziemia wysychała i pękała, co powodowało jej napowietrzanie i chroniło przed nadmiernym zasoleniem. Okres ten w egipskim kalendarzu określano jako czas suszy (szemu).

Dopiero w połowie XIX wieku ten cykliczny rytuał zaczęto stopniowo ograniczać poprzez budowę tam na Nilu. Budowa Wielkiej Tamy Asuańskiej zakończona w 1970 roku, a w efekcie powstanie Jeziora Nasera, spowodowała zupełne zaburzenie dotychczasowej relacji pomiędzy człowiekiem a otaczającym go środowiskiem naturalnym. W czasach starożytnych, kiedy mierzono wysokość przyboru wody w górnym stanie rzeki, można było z dużym prawdopodobieństwem oszacować nie tylko wielkość wylewu, lecz także określić rozmiar przewidywanych zbiorów ${ }^{10}$. W dziejach cywilizacji faraonów pojawiały się niszczące i wyjątkowo obfite przypływy, czasami zaś wyjątkowo skąpe, ledwo zauważalne fale przyboru. Ich niecodzienność była tak wielkim wydarzeniem, że w dokumentach odnotowywano je i ich dramatyczne skutki. Przykładem może być niski stan wylewów, który utrzymywał się zapewne przez wiele lat pod koniec III tysiąclecia p.n.e., w czasach panowania władców zaliczanych do dynastii VII-XI. Czas ten w periodyzacji dziejów Egiptu określa się mianem Pierwszego Okresu Przejściowego, związanego z rozbiciem kraju na liczne niewielkie księstwa zarządzane przez lokalnych nomarchów. W tym okresie nie było jednego króla, który zasiadał na tronie Obu Krajów, ale wielu, z których każdy uważał siebie za potomka budowniczych wielkich piramid. O latach suszy, które zapanowały w Egipcie, dowiadujemy się przede wszystkim z ich biografii zapisywanych na stelach i ścianach grobowców. Sytuację Egiptu wynikającą z klęski nieurodzaju przedstawiono w następujący sposób:

grzebałem umarłych i karmiłem żywych wszędzie, dokąd tylko udałem się podczas głodu, który nastał $[\ldots]^{11}$,

${ }^{9}$ B. Olsen, W obronie rzeczy. Archeologia i ontologia przedmiotów, przeł. B. Shallcross, Warszawa 2013, s. 246.

${ }^{10}$ H. Jaritz, Nilmesser, [w:] Lexikon der Ägyptologie, t. 4. Megiddo-Pyramiden, red. E. Otto, W. Helck, W. Westendorf, Wiesbaden 1982, s. 496-498.

${ }^{11}$ Fragment tekstu ze steli Merera odkrytej w Edfu, obecnie znajdującej się w zbiorach Muzeum Narodowego w Krakowie. Tekst thumaczenia za: T. Wilkinson, Powstanie i upadek starożyt- 
posłałem górnoegipski jęczmień do Juni i do Hefat, (dopiero jednak) po nakarmieniu Imitru $[\ldots]^{12}$.

Zdecydowanie obszerniejszy opis wydarzeń związanych z wojną domową, a przede wszystkim z jedną z jej głównych przyczyn — suszą — zaoferował nam nomarcha o imieniu Anchtifi:

Cały Górny Egipt przymierał głodem i doszło do tego, że każdy zjadał własne dzieci. To ja nie pozwoliłem, by ludzie umierali z głodu w tym nomie. Ja dałem Górnemu Egiptowi pożyczkę w zbożu, a Północy dałem zboże Górnego Egiptu. I nie słyszałem, by podobną rzecz uczynił ktoś $\mathrm{z}$ nomarchów przede mną $[\ldots]^{13}$.

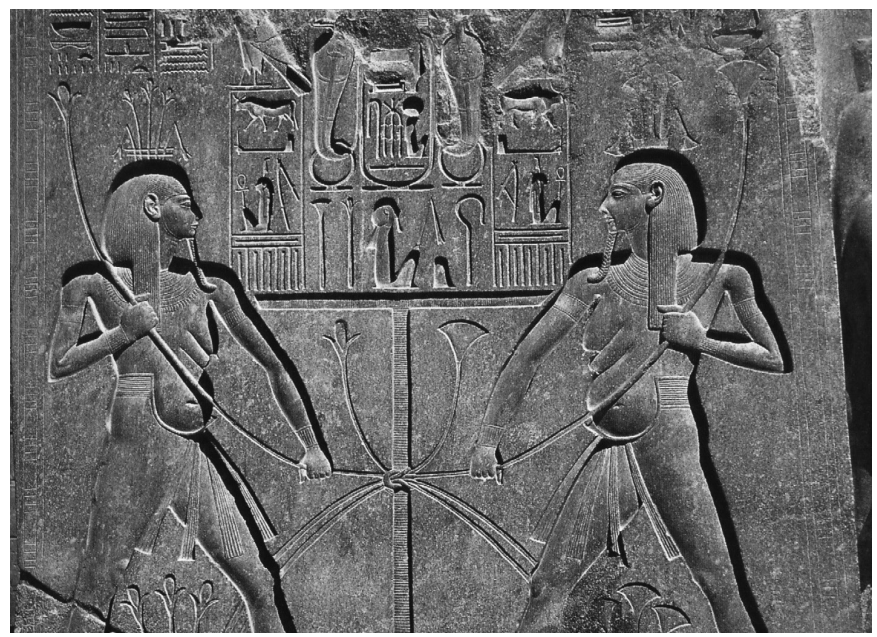

Ilustracja 1. Bóg Hapi reprezentujący Nil północny i południowy.

Przedstawienie z posągu Ramzesa II w świątyni w Luksorze

Źródło: R.H. Wilkinson, The Complete Gods and Goddesses of Ancient Egypt, London 2003, s. 107.

nego Egiptu. Dzieje cywilizacji od 3000 p.n.e. do czasów Kleopatry, przeł. N. Radomski, Poznań 2011, s. 582. Więcej na temat steli Merera zob. J. Černý, The stela of Merer in Cracow, „Journal of Egyptian Archaeology" 47, 1961, s. 5-9, pl. I; W. Schenkel, Memphis - Hearkleopolis Theben. Die Epigraphischen Zeugnisse der 7.-11. Dynastie Ägyptens, Wiesbaden 1965, s. 62-64; M. Lichtheim, Ancient Egyptian Literature, t. 1. The Old and Middle Kingdoms, Berkeley-Los Angeles-London 1975, s. 87-88; D. Gorzelany, Galeria sztuki starożytnej Muzeum Narodowego w Krakowie. Przewodnik, Kraków 2011, s. 80-81, fig. 45.

${ }^{12}$ Fragment tekstu ze steli Itiego, obecnie znajdującej się w zbiorach Muzeum Egipskiego w Kairze, CG 20001. Tekst thumaczenia za: T. Wilkinson, op. cit., s. 582. Więcej na temat steli Itiego zob. H.O. Lange, H. Schäfer, Grab- und Denksteine des Mittleren Reichs im Museum von Kairo. No. 20001-20780, cz. 1, Berlin 1902, s. 1-2; J. Vandier, La stele 20.001 du Musée du Caire, „Mélanges Maspero” 1, 1935, „Mémoires Publiés Par Les Membres De L'institut Français D’archéologie Orientale Du Caires" 46, s. 137-145; M. Lichtheim, op. cit., s. 88-89.

13 J. Vandier, Mo 'alla. La tombe d'Ankhtifi et la tombe de Séekhotep, „Bibliothèque d'étude” 18, Le Caire 1950, s. 220-231, thum. za: N. Grimal, Dzieje starożytnego Egiptu, przeł. A. Łukaszewicz, Warszawa 2006, s. 154. 
Całe jednak wieki rzeka wylewała dość regularnie i w sposób dający się przewidzieć. Owa życiodajność i regularność dostarczania wody oraz żyznych mułów doprowadziła do jej ubóstwienia. Nil był kojarzony z bóstwem Hapi (zob. ilustracja 1), a to łączyło się $\mathrm{z}$ wiarą $\mathrm{w}$ jego pochodzenie od bezkresnego praoceanu ${ }^{14}$. Hapi ukazywany był jako mężczyzna o obfitych kształtach z obwisłymi piersiami karmiącej kobiety, przepasany pasem rybaka oraz z pękiem trzcin na głowie. Na malowidłach jego ciało pokrywano kolorami zielonym i niebieskim, czyli barwami związanymi z wodą i odrodzeniem. Starożytni Egipcjanie wierzyli bowiem, że świat w formie kamienia, który nazywali benben, wyłonił się z praoceanu. Zgodnie z mitologią wszelakie życie również miało swój początek w wodzie.

Wspomniany życiodajny aspekt wody dostrzec można również w sposobie rozplanowania egipskich osad. Zarówno w czasach starożytnych, jak i obecnie osadnictwo koncentrowało się w dolinie i delcie Nilu oraz w obrębie kilku oaz położonych na pustyni. Gospodarstwa lokalizowano w niewielkiej odległości od wody; z każdej strony otaczały je pola. Krajobraz ten do dzisiaj w wielu miejscach Egiptu pozostaje niezmieniony. Niewielkie wsie ukryte są gajach palmowych, zaś dookoła rozciągają się tereny uprawne. W trakcie wylewu wody Nilu zalewały tereny uprawne, sięgając niekiedy poza linię osadnictwa. Wówczas wsie i miasta wystawały ponad lustro stojącej wody, tworząc wyspy połączone z sobą groblami.

Relacja pomiędzy człowiekiem a środowiskiem nie ograniczała się jedynie do zbierania plonów z obszarów, na które podczas wylewu docierały wody Nilu akumulujące żyzny muł. Już w najdawniejszych czasach, w trakcie formowania się kultury egipskiej, rozpoczęto kopanie kanałów i budowanie tam na terenach, gdzie wezbrane wody rzeki dotychczas nie docierały. Egipcjanie nie ograniczali się zaledwie do obserwacji poziomu wody za pomocą wspomnianych nilometrów, ale rozwinęli przede wszystkim system irygacji oraz regulacji stanu wody w sztucznych zbiornikach. Umożliwiało to zgromadzenie wody na pewien czas po wylewie, co pozwalało na dodatkowe nawadnianie pól przez dłuższy okres, dając niekiedy drugi zbiór.

Ponadto pola znajdujące się poza zasięgiem wód Nilu podczas wylewu można było nawadniać za pomocą systemu urządzeń podnoszących wodę na wyższy poziom. Służył do tego między innymi szaduf, czyli proste drewniane urządzenie w formie żurawia - długiej żerdzi osadzonej na pionowym trzpieniu, funkcjonujące na zasadzie dźwigni wykorzystującej przeciwwagę (zob. ilustracja 2) ${ }^{15}$.

${ }^{14} \mathrm{Na}$ temat boga Hapi w mitologii egipskiej por. J. Lipińska, Mitologia starożytnego Egiptu, Warszawa 2002, s. 161; G. Pinch, Handbook of Egyptian Mythology, Oxford 2002, s. 136-137; R.H. Wilkinson, The Complete Gods and Goddesses of Ancient Egypt, London 2003, s. 106-108. Zob. też Hymn do Nilu = Papirus Anastasi 7, The British Museum, EA 10222, http://www.britishmuseum.org/research/collection_online/collection_object_details.aspx?objectId=113846\&partId $=1 \&$ searchText=10222\&page $=1$ (dostęp: 3 września 2018). Tłumaczenie i komentarz tekstu zob. W. Helck, Der Text des „,Nilhymnus”, Wiesbaden 1972; J. Assmann, Ägyptische Hymnen und Gebete, Freiburg 1999, s. 540-547.

15 A. Wilkinson, The Garden in Ancient Egypt, London 1998, s. 20-29. 
Przenoszona w ten sposób woda wykorzystywana była nie tylko do nawadniania pól, lecz także do podlewania przydomowych ogrodów, których przedstawienia można znaleźć w formie malowideł na ścianach grobowców. Ogrody powstawały jednak nie tylko w obrębie osiedli mieszkalnych, ale też na terenie nekropoli. Jednym z najsłynniejszych odkrytych dotychczas tego typu przykładów był ogród w obrębie zespołu świątynno-grobowego Nebhepetre Mentuhotepa II w Deir el-Bahari ${ }^{16}$. Drzewa posadzone zostały na terenie głównego dziedzińca przed wejściem do świątyni grobowej władcy. Rosły w kilku rzędach po obu stronach alei procesyjnej, dodatkowo pogrupowano je ze względu na gatunki. W rzędach biegnących wzdłuż alei od strony wejścia do świątyni posadzono sykomory, zaś w dalszej części rosły tamaryszki. Przed posadzeniem każdego z drzew wydrążono w skalnym podłożu okrągłe zagłębienie, a następnie wypełniono je mułem nilowym. Ponadto po południowej stronie alei procesyjnej w trakcie wykopalisk odsłonięto podłużne zagłębienie, w którym posadzono różne gatunki kwiatów ${ }^{17}$.

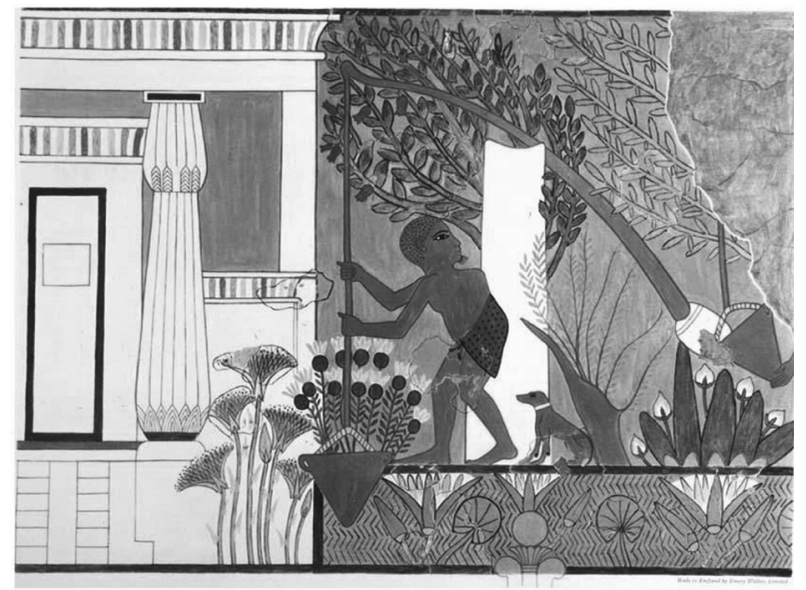

Ilustracja 2. Podlewanie ogrodu z wykorzystaniem szadufa

Źródło: N. de Garis Davies, Two Ramesside Tombs at Thebes, New York 1927, pl. 30.

Wraz z rozwojem systemu irygacyjnego zaczęły postępować również zmiany społeczne. W rezultacie doszło do wykształcenia się lokalnej warstwy zarządzającej, która z czasem przerodziła się w zależną od władcy scentralizowaną administrację państwową pobierającą podatki od uprawiających ziemię rolników. Chłopi, jako najniższa, a zarazem najliczniejsza warstwa społeczna, byli odpowiedzialni za funkcjonowanie tam oraz przepustowość kanałów, a także dbanie o wały otaczające zbiorniki, w których gromadzono wodę. Wysokie zbiory pozwoliły z cza-

${ }^{16}$ H.E. Winlock, Excavations at Thebes, „Metropolitan Museum of Art Bulletin” 17/12/2, 1922, s. 24-26; idem, The tombs of the kings of the seventeenth dynasty at Thebes, „Journal of Egyptian Archaeology" 10, 1924, s. 5.

17 D. Arnold, The Temple of Mentuhotep at Deir el-Bahari, New York 1979, s. 22. 
sem na wykształcenie się dalszych grup społecznych, takich jak rzemieślnicy i kupcy, z których efektów pracy korzystali głównie najbogatsi Egipcjanie.

Kolejnym wartym uwagi aspektem jest to, co Nil dawał Egipcjanom bezpośrednio. Prócz wspominanej wcześniej wody i nawożącego ich pola mułu dostarczał bowiem również bogactwa zwierząt i roślin, które w niemałym stopniu wpływały na życie ludzi. Jednym z podstawowych wymiarów życia starożytnych Egipcjan były połowy ryb oraz polowania na ptactwo wodne, ale też na żyjące tam ssaki. Polowanie na niektóre z nich miało na celu nie tylko dostarczenie pożywienia, lecz było także istotnym elementem kultury czy wręcz religii. Takimi zwierzętami były między innymi groźne gatunki, takie jak krokodyl czy hipopotam. $Z$ tym ostatnim związane były przedstawienia władcy, który za pomocą włóczni przebijał zwierzę, nawiązując w ten sposób do mitu o Horusie i Secie, czyli legendarnego zwycięstwa dobra nad złem. Faraon utożsamiany był w tych przedstawieniach z Horusem jako gwarant ładu i porządku (maat) na ziemi; zabijał hipopotama, pod postacią którego przedstawiano boga Seta - pana chaosu ${ }^{18}$. Polowanie na wodzie to również częsty motyw malarski w grobach wielmożów, w których pokazuje się ulubione rozrywki, jakim oddawano się za życia.

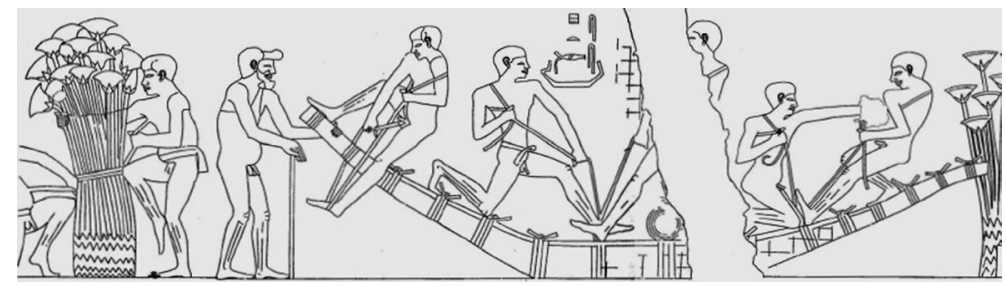

Ilustracja 3. Wyplatanie łodzi z łodyg papirusu

Źródło: A.M. Blackman, The Rock Tombs of Meir, cz. 2. The Tomb-Chapel of Senbi's son Ukh-Hotp (B, no. 2), London 1915, pl. IV.

Oprócz bogatej gamy gatunków zwierząt Nil stanowił miejsce pozyskania papirusu, z którego wytwarzano maty, kosze, sandały, sznury i materiał piśmienniczy. Ponadto długie łodygi papirusu znakomicie nadawały się do konstruowania trzcinowych łodzi, co miało znaczący wpływ na rozwój transportu. Łodzie wykonane z papirusu, znane od najdawniejszych czasów w dziejach Egiptu, służyły głównie do polowania i przemieszczania się niewielkich grup ludzi. Ich wyplatanie wielokrotnie ukazują malowidła w grobowcach (zob. ilustracja 3). Z papirusu konstruowano również kilkunastometrowe łodzie transportowe ${ }^{19}$.

Do przewozu cięższych materiałów, na przykład kamiennych bloków do budowy świątyń czy grobowców, a nawet kilkunastometrowej długości, wielotonowych obelisków, konstruowano łodzie drewniane. Głównymi materiałami do ich

18 J. Lipińska, op. cit., s. 47 n.

19 R. Partridge, Transport in Ancient Egypt, London 1996, s. 13-23. 
budowy były lokalne drzewa, takie jak akacja, sykomora i persea, a także gatunki importowane, jak cedr, który pozyskiwano na terenie dzisiejszego Libanu.

Wśród znanych rodzajów łodzi można wymienić między innymi statki służące do transportu różnych materiałów i ludzi, łodzie bojowe, a także barki pełniące funkcje kultowe, którymi podczas świąt przewożono figurę bóstwa ${ }^{20}$. Ich rozmiary, kształty oraz sposób konstruowania znane są zarówno z zachowanych przykładów łodzi, malowideł i reliefów, jak i modeli wykonywanych z drewna lub gliny. Drewniane modele łodzi wkładano bowiem do grobowców od końca Starego Państwa. Jednym z najsłynniejszych zespołów przedstawień tego typu jest grupa modeli odkryta w grobowcu Meketre w Tebach Zachodnich ${ }^{21}$.

W 1920 roku Herbert E. Winlock znalazł w posadzce głównego korytarza grobowca wejście prowadzące do niedużego szybu. Na jego dnie mieściło się niewielkie pomieszczenie, w którym od blisko 4 tysięcy lat znajdował się zespół drewnianych modeli wyobrażających łodzie wraz z załogami, browar, warsztat tkacki i rzeźnię, a także ludzi i zwierzęta.

Istotną grupę stanowiły barki grobowe, wykorzystywane w trakcie pielgrzymki do Abydos, która była jednym z etapów pogrzebu (zob. ilustracja 4). Po zakończeniu mumifikacji ciało zmarłego wkładano do trumny, którą ustawiano na specjalnej barce. Ta ciągnięta była następnie w górę lub w dół rzeki w kierunku Abydos, które było miejscem kultu boga Ozyrysa — władcy Krainy Umarłych. Tego typu łodzie znane są między innymi z grobowców królewskich. Ich najlepszym przykładem jest łódź o długości ponad 43 metrów odkryta przy piramidzie Cheopsa w Gizie ${ }^{22}$.

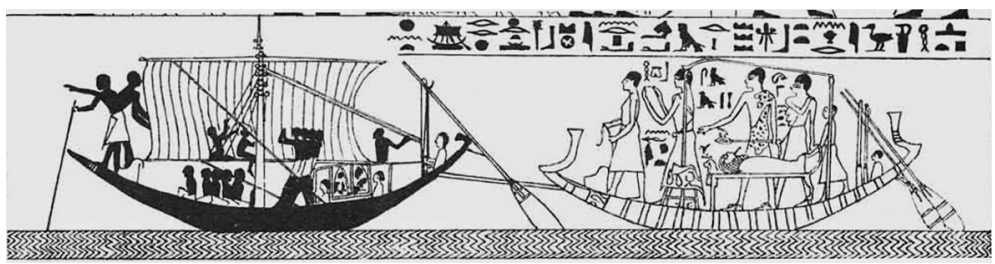

Ilustracja 4. Pielgrzymka z ciałem zmarłego do Abydos. Malowidło z grobowca Chnumhotepa w Beni Hasan

Źródło: P.E. Newberry, Beni Hasan, cz. 1, London 1893, pl. XXIX.

Nil był zatem nie tylko miejscem pozyskiwania surowca na łodzie, lecz przede wszystkim pełnił funkcję głównego szlaku w kraju. Rzeka przepływająca przez

${ }^{20}$ Ibidem, s. 24-75.

${ }^{21}$ H.E. Winlock, The Egyptian expedition 1918-1920: Excavation at Thebes 1919-1920, ,Metropolitan Museum of Art Bulletin" 15/12, 1920, s. 14-32; idem, Excavations at Thebes, 1922-1931, New York 1942, s. 17-30; idem, Models of Daily Life in Ancient Egypt from the Tomb of Meket-Re' at Thebes, New York 1955.

22 N. Jenkins, The Boat Beneath the Pyramid, New York 1980. 
cały Egipt umożliwiała zarówno przemieszczanie się na niewielkie odległości, jak i dalekie podróże. Żegluga w górę rzeki przebiegała przy rozwiniętych żaglach, co umożliwiały wiatry wiejące z północy. Z kolei podróż w dół Nilu odbywała się z prądem rzeki lub wymagała użycia wioseł. Ta podstawowa różnica wynikająca z kierunku podróży znalazła swoje odzwierciedlenie również w zapisie hieroglificznym odnoszącym się do żeglowania na południe oraz podróży na północ.

Rzeka nie tylko umożliwiała przemieszczanie się na terenie Egiptu, ale też żegluge poza jego granice, co miało istotne znaczenie dla rozwoju handlu. Ponadto Nil, przepływając tysiące kilometrów, z głębi Afryki ku Morzu Śródziemnemu, spinał spore obszary całego kontynentu. $Z$ tego powodu w czasach ptolomejskich i rzymskich był częścią ogromnego szlaku handlowego, który łączył Europę ze szlakami morskimi na Oceanie Indyjskim ku Azji.

Wielu badaczy powołuje się na Herodota, który w swojej Historii określa Egipt „darem Nilu”23. Środowisko naturalne, którego dla Egiptu szczególnie ważnym elementem jest życiodajna rzeka, na całe wieki zdominowało życie jego mieszkańców, wpływając na praktycznie wszystkie aspekty ich cywilizacji oraz kultury. Choć w tłumaczeniach Historii pojawia się Nil, autor używa greckiego słowa $\pi o \tau \alpha \mu o \tilde{v}$, czyli „rzeka”. Pojawia się też słowo $\delta \tilde{\omega} \rho v^{24}$, które oznacza 'dar, prezent' ${ }^{25}$, występujące w Ewangelii według św. Mateusza, gdzie o Mędrcach, którzy przybyli zobaczyć narodziny Dziecięcia, czytamy: „otworzywszy swe skarby, ofiarowali Mu dary" (Mt 2, 11).

Bjørnar Olsen, powołując się na Alfreda Gella, pyta i odpowiada: ,jak rzeczy oddziaływają i odnoszą się do ludzi [...]. Sprawczość jest robieniem — interaktywną relacją między istnieniami — nie zaś rzadkim towarem posiadanym tylko przez ludzi” ${ }^{26}$. Dodaje też: „Skuteczność i użyteczność rzeczy wynika nie tylko [z] ich używania przez ludzi, lecz także z faktu, że są 'zdolne do oddziaływania' [...]"27. Jeśli więc przyjmiemy, że działanie nie jest jedynie przywilejem człowieka, lecz także rzeczy, to słowa Herodota moglibyśmy rozumieć nie tylko jako metaforę. Rzeka płynie, niesie z sobą muł, zmienia prędkość nurtu, podnosi poziom, wylewa, obniża poziom i wycofuje się z zalanych terenów, pozostawia je nawodnione i wzbogacone w składniki mineralne i organiczne. Marcel Mauss zauważył, że aktowi darowania towarzyszy rewanż, a samemu darowi — dar zwrotny, a zatem

${ }^{23}$ Herodotus, Book 2: Euterpe, 1890, księga 2, rozdział 5, http://www.sacred-texts.com/cla/hh/ hh2000.htm (dostęp: 28 września 2017).

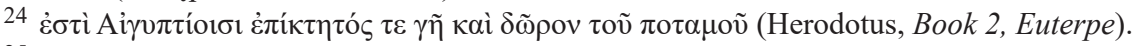

25 J.H. Thayer, Greek-English Lexicon to the New Testament, Harrington 2013.

26 B. Olsen, W obronie rzeczy. Archeologia i ontologia przedmiotów, przeł. B. Shallcross, Warszawa 2013, s. 209.

${ }^{27}$ Ibidem, s. 239. 
dar i obdarowywanie są często częścią trwającej w czasie dynamicznej interakcji nieograniczającej się wyłącznie do tego, że jedna strona daje, a druga bierze ${ }^{28}$.

Olsen zauważa też: „Życie z rzeczami nie jest oczywiście statycznym zaangażowaniem. Rzeczy przemieniają nasze życie i same, przynajmniej w pewnym stopniu, zmieniają się przez to wzajemne zaangażowanie"29. Omawia przy tym związek zachodzący pomiędzy myśliwym Inuitą, zjednoczonym ze swym kajakiem, gdy pływają po wodach Arktyki, ale my jego słowa możemy odnieść również do związku zachodzącego przez stulecia i tysiąclecia między mieszkańcami Egiptu a ich rzeką. Przykładem zmian, jakim ona uległa, jest zarówno wybudowany i stale konserwowany oraz rozbudowywany system kanałów rozprowadzających jej wody, jak i tamy i elektrownie wybudowane już w XX wieku. Gdy my, ludzie, możliwość działania przypisujemy tylko sobie, myślimy o tym, że to my ujarzmiamy rzeki. Z przywołanych uwag możemy jednak wyciągnąć wniosek, że równie prawdziwe lub równie nieprawdziwe jest stwierdzenie, że to Nil ujarzmił Egipt, aczkolwiek właściwym określeniem byłoby „wzajemne zaangażowanie” między ludźmi i rzeką, które zmienia z upływem czasu i ludzi, i rzekę, i siebie.

\section{The role of the Nile river in the formation of the ancient Egyptian culture}

\section{Abstract}

The aim of this paper is to describe the main points of the multifaceted relations between Nile and the culture and civilization of ancient Egypt. Both economic and cultural matters are indicated. The Nile fed, drank, irrigated the fields, served as a communication route, but besides, it went into the beliefs and cultural world of the Egyptians. The regulation of the rhythm of people's lives, their social organization, cult behaviours, ritual hunting, ways of spending free time, or numerous works of art were connected with Nile. In fact, it is difficult to find anything in Egypt during the pharaonic era that was not connected with it. It has been a key factor in the lives of people in Egypt for thousands of years.

Keywords: Nile, economy, culture, beliefs, social organization

\section{Bibliografia}

Arnold D., The Temple of Mentuhotep at Deir el-Bahari, New York 1979.

Assmann J., Ägyptische Hymnen und Gebete, Freiburg 1999.

28 M. Mauss, Szkic o darze. Formy i podstawa wymiany w spoleczeństwach archaicznych, [w:] idem, Socjologia i antropologia, przeł. K. Pomian, Warszawa 1973, s. 211-421.

${ }^{29}$ B. Olsen, op. cit., s. 228. 
Blackman A.M., The Rock Tombs of Meir, cz. 2. The Tomb-Chapel of Senbi's son Ukh-Hotp (B, no. 2), London 1915.

Butzer K.W., Early Hydraulic Civilization in Egypt. A Study in Cultural Ecology, Chicago-London 1976.

Chudzik P., The tombs of Asasif: Archaeological exploration in the 2013/2014 season, „Polish Archaeology in the Mediterranean" 24, 2015.

Černý J., The stela of Merer in Cracow, „Journal of Egyptian Archaeology” 47, 1961.

Davies N. de Garis, Two Ramesside Tombs at Thebes, New York 1927.

Drobniewicz, B., Ginter B., Kozłowski J.K., Topographie préhistorique du cirque de Deir el-Bahari, [w:] Deir el-Bahari (Habitat préhistorique), cz. 1, red. J.K. Kozłowski, „Prace Archeologiczne” 24, 1976.

Ginter B., Kozłowski J.K., Drobniewicz B., Silexindustrien von El Târif, „Archäologische Veröffentlichungen" 26, Mainz 1986.

Gorzelany D., Galeria sztuki starożytnej Muzeum Narodowego w Krakowie. Przewodnik, Kraków 2011.

Grimal N., Dzieje starożytnego Egiptu, przeł. A. Łukaszewicz, Warszawa 2006.

Helck W., Der Text des ,,Nilhymnus”, Wiesbaden 1972.

Hendrick S., Vermeersch P., Prehistory. From the Palaeolithic to the Badarian Culture (c. 7,000,0004000 BC), [w:] The Oxford History of Ancient Egypt, red. I. Shaw, Oxford 2000.

Herodot, The History of Herodotus, przeł. G.C. Macaulay, London, http://www.gutenberg.org/ files/2707/2707-h/2707-h.htm\#link22H_4_0001.

Herodotus, Book 2: Euterpe, http://www.sacred-texts.com/cla/hh/hh2000.htm.

Hodder I., Entangeld. An Archaeology of the Relationships between Humans and Things, Malden 2012.

Hymn do Nilu = Papirus Anastasi 7, The British Museum, EA 10222, http://www.britishmuseum. org/research/collection_online/collection_object_details.aspx?objectId=113846\&partId=1\&sea rchText $=10222$ \&page $=1$.

Jaritz H., Nilmesser, [w:] Lexikon der Ägyptologie, t. 4. Megiddo-Pyramiden, red. E. Otto, W. Helck, W. Westendorf, Wiesbaden 1982.

Jenkins N., The Boat Beneath the Pyramid, New York 1980.

Lange H.O., Schäfer H., Grab- und Denksteine des Mittleren Reichs im Museum von Kairo. No. 20001-20780, cz. 1, Berlin 1902.

Lichtheim M., Ancient Egyptian Literature, t. 1. The Old and Middle Kingdoms, Berkeley-Los Angeles-London 1975.

Lipińska J., Mitologia starożytnego Egiptu, Warszawa 2002.

Mauss M., Szkic o darze. Formy i podstawa wymiany w spoleczeństwach archaicznych, [w:] idem, Socjologia i antropologia, przeł. K. Pomian, Warszawa 1973.

Midant-Reynes B., The Prehistory of Egypt: From the First Egyptians to the First Pharaohs, przeł. I. Shaw, Oxford 2000.

Newberry P.E., Beni Hasan, cz. 1, London 1893.

Olsen B., W obronie rzeczy. Archeologia i ontologia przedmiotów, przeł. B. Shallcross, „Nowa Humanistyka" 2, Warszawa 2013.

Partridge R., Transport in Ancient Egypt, London 1996.

Pinch G., Handbook of Egyptian Mythology, Oxford 2002.

Schweinfurth G., Ein neuentdecker Tempel in Theben, „Zeitschrift für Ägyptische Sprache und Altertumskunde" 41, 1904.

Schweinfurth G., Über altpaläolitische Manufakte aus dem Sandsteingebiet von Oberägypten, „Zeitschrift für Ethnoogie” 5, 1909.

Schenkel W., Memphis - Hearkleopolis - Theben. Die Epigraphischen Zeugnisse der 7.-11. Dynastie Ägyptens, Wiesbaden 1965. 
Thayer J.H., Greek-English Lexicon to the New Testament, Harrington 2013.

Vandier J., La stele 20.001 du Musée du Caire, „Mélanges Maspero” 1, 1935, „Mémoires Publiés Par Les Membres De L'institut Français D'archéologie Orientale Du Caires” 46.

Vandier J., Mo'alla. La tombe d'Ankhtifi et la tombe de Séekhotep, „Bibliothèque d'étude” 18, Le Caire 1950.

Wilkinson A., The Garden in Ancient Egypt, London 1998.

Wilkinson R.H., The Complete Gods and Goddesses of Ancient Egypt, London 2003.

Wilkinson T., Powstanie i upadek starożytnego Egiptu. Dzieje cywilizacji od 3000 p.n.e. do czasów Kleopatry, przeł. N. Radomski, Poznań 2011.

Winlock H.E., Excavations at Thebes, „Metropolitan Museum of Art Bulletin” 17, 1922, nr 12, z. 2.

Winlock H.E., Excavations at Thebes, 1911-1931, New York 1942.

Winlock H.E., Models of Daily Life in Ancient Egypt from the Tomb of Meket-Re' at Thebes, New York 1955.

Winlock H.E., The Egyptian expedition 1918-1920: Excavation at Thebes 1919-1920, „Metropolitan Museum of Art Bulletin" 15, 1920, nr 12.

Winlock H.E., The tombs of the kings of the seventeenth dynasty at Thebes, „Journal of Egyptian Archaeology" 10, 1924. 